STUDI

FRANCESI

\section{Studi Francesi}

Rivista quadrimestrale fondata da Franco Simone

Varia

\title{
Jörn Steigerwald, Marine Roussillon (dir.), La dispute entre l'Arioste et le Tasse. Les appropriations de deux esthétiques antagonistes au XVII siècle en France
}

Laura Rescia

\section{OpenEdition}

Journals

\section{Edizione digitale}

URL: http://journals.openedition.org/studifrancesi/1144

DOI: 10.4000/studifrancesi. 1144

ISSN: 2421-5856

\section{Editore}

Rosenberg \& Sellier

\section{Edizione cartacea}

Data di pubblicazione: 1 novembre 2014

Paginazione: 593

ISSN: 0039-2944

Notizia bibliografica digitale

Laura Rescia, « Jörn Steigerwald, Marine Roussillon (dir.), La dispute entre l'Arioste et le Tasse. Les appropriations de deux esthétiques antagonistes au xvı" siècle en France », Studi Francesi [Online], 174 (LVIII | III) | 2014, online dal 01 novembre 2014, consultato il 18 septembre 2020. URL : http:// journals.openedition.org/studifrancesi/1144; DOI : https://doi.org/10.4000/studifrancesi.1144

Questo documento è stato generato automaticamente il 18 settembre 2020.

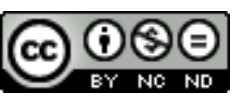

Studi Francesi è distribuita con Licenza Creative Commons Attribuzione - Non commerciale - Non opere derivate 4.0 Internazionale. 


\title{
Jörn Steigerwald, Marine Roussillon (dir.), La dispute entre l'Arioste et le Tasse. Les appropriations de deux esthétiques antagonistes au XVII siècle en France
}

\author{
Laura Rescia
}

\section{NOTIZIA}

Jörn STEIGERWALD, Marine ROUSSILLON (dir.), La dispute entre l'Arioste et le Tasse. Les appropriations de deux esthétiques antagonistes au XVII siècle en France, «Papers on French Seventeenth Century Literature», vol. XL, n. 79, 2013.

1 Gli ormai classici testi di A. Cioranescu e di C.B. Beall sulla fortuna rispettivamente dell'Ariosto e del Tasso in Francia, sebbene insuperati sul piano dell'erudizione, attendevano un rinnovamento nello sguardo critico d'insieme. È quanto si annuncia con questa raccolta di studi, che testimonia una rinnovata attenzione critica sull'influenza, compresente o avvicendata, delle due maggiori poetiche del Cinquecento italiano sullo sviluppo dei generi epico e romanzesco nella Francia secentesca; alcuni interventi riguardano inoltre gli influssi delle medesime poetiche sulla commedia e sui balletti di corte.

2 Jörn STEIGERWALD, De la querelle entre l'Arioste et le Tasse à la dispute entre l'esthétique de l'Arioste et celle du Tasse, pp. 233-259, presenta un denso studio che prende le mosse dalla constatazione di una sorta di crasi effettuatasi nella ricezione francese dei due italiani, avvenuta con la frequente fusione di soggetti ariosteschi declinati in forme tassiane. L'A. ipotizza che tutta la concezione della Francia galante del XVII secolo derivi proprio dalla configurazione congiunta dei due influssi. L'articolo tratteggia la questione della 
querelle tra partigiani delle due opposte poetiche alla fine del XVI secolo, per poi anticipare qualche scorcio di uno studio approfondito del passaggio alla nuova estetica "ariosto-tassiana" alla corte di Louis XIV.

Dorothee LINTNER, Appropriations comiques du Tasse et de l'Arioste à travers quelques histoires comiques $d u$ XVII siècle, pp. 261-175, si concentra su un genere poco indagato in relazione alle due poetiche in questione, e nel quale è possibile rintracciare una doppia tendenza: nascosta dietro ad un'esplicita, dichiarata preferenza per il Tasso, si può infatti intravedere una certa ammirazione per l'Ariosto. Vengono rilevati numerosi passaggi tratti dalle principali histoires comiques che sfruttano episodi del Furioso o mettono in scena la querelle tra sostenitori e avversari delle due diverse poetiche. L'A. ipotizza che tali riscritture possano testimoniare un intento emulativo invece che accusatorio nei confronti dell'autore del Furioso.

Sul genere epico si concentra l'intervento di Francine wiLD, Une référence dissymétrique: Chapelain, Desmarets, Le Moyne, Scudéry, face à l'Arioste et au Tasse, pp. 277-289, nel quale si evidenzia come entrambi gli italiani siano conosciuti e apprezzati dai poeti epici francesi secenteschi, anche se Ariosto in modo meno aperto, più dissimulato. L'epopea francese dimostra di allontanarsi dalla poetica tassiana, e di evolvere in una direzione maggiormente congrua a quella ariostesca, aprendo all'approfondimento psicologico dei personaggi, all'evoluzione degli aspetti tecnico-scientifici, e a una maggior fedeltà alla storia. Un simile atteggiamento è riscontrabile anche nel romanzo eroico, al quale è dedicato lo studio di Marie Gabrielle LALLEMAND, L'unité d'action dans les romans héroïques (Desmarets, Gomberville, La Calprenède, Scudéry), pp. 291-305. I mezzi tecnici adottati nel Furioso per creare suspense (interruzione, molteplicità di azione, inizio in medias res) trovano infatti rispondenza nell'organizzazione strutturale di molti romanzi eroici secenteschi.

5 Anne-Elisabeth SPICA, Lectures françaises du système épique tassien: un enfer pavé de bonnes intentions?, pp. 307-322 intravede, nella ricezione francese dei principi tassiani di edificazione dell'epopea, un riferimento all'eredità oraziana piuttosto che aristotelica. Per il Tasso, come noto, la verosimiglianza interna costituisce una caratteristica intrinseca dell'epopea, per conferire bontà d'animo attraverso la contemplazione della bellezza della verità. In Francia, invece, la stessa verosimiglianza è indice dell'estremizzazione dell'utile dulci oraziano, e a questo stesso concetto sono da ricondurre l'utilizzo del meraviglioso, il ruolo della storia, e lo sviluppo della figura dell'eroe.

6 Sulla trasposizione di singoli elementi dell'epopea italiana nei balletti di corte agli esordi del regno di Louis XIII è dedicata la riflessione di Marie-Claude CANOVA GREEN, Le " grand dessein » de Louis XIII: l'Arioste, le Tasse et le ballet de cour (1617-1619), pp. 323-335. L'esaltazione dell'aspetto eroico e dell'ideologia cristiana sono elementi del Furioso e della Gerusalemme tanto presenti nella trasposizione di singoli episodi nei balletti di corte francesi, quanto negletti nelle riscritture romanzesche. Il loro utilizzo, sostiene l'A., è funzionale alla costruzione di una nuova ideologia politica: così il balletto di corte ammortizza le scene di eccesso passionale, a profitto dell'immagine del giovane sovrano, valoroso guerriero desideroso di far tornare nel regno l'unità religiosa.

7 Jörn STEIGERWALD, De la comédie érudite à la comédie de salon: les appropriations de l'Arioste par Molière [...], pp. 338-361, analizza le trasformazioni ideologiche fatte subire ad elementi narrativi già presenti nel Furioso, e relative ai valori della famiglia e della 
sessualità, nel passaggio dalla commedia erudita alla comédie de salon, grazie alla triplice lettura analitica de L'école des maris, L'école des femmes e La critique de l'école des femmes. 